\title{
Novel GABA Receptor Pesticide Targets
}

\author{
John E. Casida and Kathleen A. Durkin
}

\section{Abstract}

1. GABAergic Pesticides

2. GABA Receptors

2.1 Structure and function

2.2 Target site models

3. First Generation Non-Competitive Antagonists

3.1 NCA-IA Site

\subsubsection{Structures}

3.1.2 NCA action, resistance and binding sites

3.2 NCA-IB Site

4. Second Generation Non-Competitive Antagonists: NCA-II Site

4.1 Structures

4.2 NCA action

4.3 Resistance and NCA-II binding site

5. Allosteric Modulator (AVE)

6. Four Distinct Binding Sites

6.1 Radioligand binding assays

6.2 Toxicological relevance

6.3 Overlapping and coupled sites

6.4 Selective toxicity

6.5 Cross resistance

7. Prospects 
Manuscript prepared for

possible publication in:

Pestic. Biochem. Physiol.

Invited paper for the Special Issue

Insecticide Mode of Action and Resistance

Submitted: August 22 ${ }^{\text {nd }}, 2014$

Revised: November 18, 14 $\underline{\text { Return comments and proofs to: }}$

Dr. John E. Casida

Environmental Chemistry and

Toxicology Laboratory

Department of Environmental

Science, Policy and Management

114 Wellman Hall

University of California

Berkeley, California 94720-3112

Tel. (510) 642-5424

Fax. (510) 642-6497

Email: ectl@berkeley.edu

\title{
Novel GABA Receptor Pesticide Targets
}

\author{
John E. Casida ${ }^{1, *}$ and Kathleen A. Durkin ${ }^{2}$ \\ ${ }^{1}$ Environmental Chemistry and Toxicology Laboratory, Department of Environmental Science, \\ Policy, and Management, University of California, Berkeley, California 94720-3112 \\ ${ }^{2}$ Molecular Graphics and Computation Facility, College of Chemistry, University of California, \\ Berkeley, California 94720-1460 \\ Corresponding author. Tel. +1-510-642-5424; fax +1-510-642-6497; email: ectl@berkeley.edu
}




\section{Abstract:}

The $\gamma$-aminobutyric acid (GABA) receptor has four distinct but overlapping and coupled targets of pesticide action importantly associated with little or no cross resistance. The target sites are differentiated by binding assays with specific radioligands, resistant strains, site-directed mutagenesis and molecular modeling. Three of the targets are for non-competitive antagonists (NCAs) or channel blockers of widely varied chemotypes. The target of the first generation $\left(20^{\text {th }}\right.$ century) NCAs differs between the larger or elongated compounds (NCA-IA) including many important insecticides of the past (cyclodienes and polychlorocycloalkanes) or present (fiproles) and the smaller or compact compounds (NCA-IB) highly toxic to mammals and known as cage convulsants, rodenticides or chemical threat agents. The target of greatest current interest is designated NCA-II for the second generation ( $21^{\text {st }}$ century) of NCAs consisting for now of isoxazolines and meta-diamides. This new and uniquely different NCA-II site apparently differs enough between insects and mammals to confer selective toxicity. The fourth target is the avermectin site (AVE) for allosteric modulators of the chloride channel. NCA pesticides vary in molecular surface area and solvent accessible volume relative to avermectin with NCA-IBs at $20-22 \%$, NCA-IAs at $40-45 \%$ and NCA-IIs at 57-60\%. The same type of relationship relative to ligand-docked length is $27-43 \%$ for NCA-IBs, $63-71 \%$ for NCA-IAs and $85-105 \%$ for NCA-IIs. The four targets are compared by molecular modeling for the Drosophila melanogaster GABAR. The principal sites of interaction are proposed to be: pore V1' and A2' for NCA-IB compounds; pore A2', L6' and T9' for NCA-IA compounds; pore T9' to S15' in proximity to M1/M3 subunit interface (or alternatively an interstitial site) for NCA-II compounds; and M1/M3, M2 interfaces for AVE. Understanding the relationships of these four binding sites is important in resistance management and in the discovery and use of safe and effective pest control agents.

Word Count: (298 words)

\section{Abbreviations:}

ave, avermectin; AVE, ave target; BPB, benzamidophenylbenzamide; Dm, Drosophila melanogaster; EBOB, 4'-ethynyl-4- $n$-propylbicycloorthobenzoate; flu, fluralaner; GABA, $\gamma$ aminobutyric acid; GABA-R, GABA receptor; $\mathrm{GABA}_{\mathrm{A}} \mathrm{R}$, GABA-R of mammalian brain; IRAC, Insecticide Resistance Action Committee; mDA, meta-diamide; NCA, non-competitive antagonist; NCA-IA, NCA-IB, NCA-II, three NCA targets; RDL, insect GABA-R; TBPS, 4-tbutylbicyclophosphorothionate

\section{Keywords:}

GABA receptor; insecticide; isoxazoline; meta-diamide; radioligand 
Graphical Abstract:

38

Same as Figure 6.

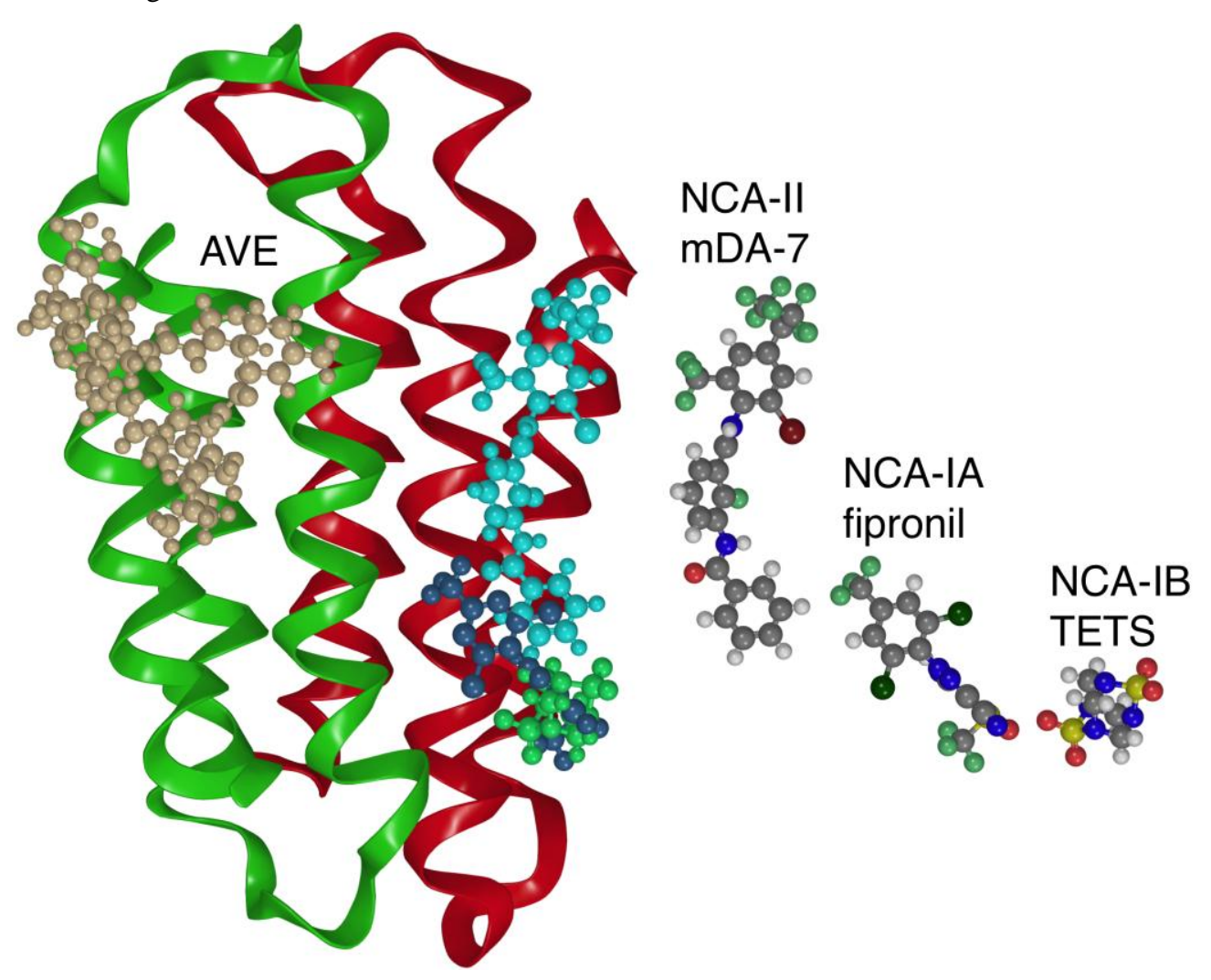

40 


\section{GABAergic Pesticides}

Our continuing ability to control pests that compete for food and fiber and transmit disease is dependent on the discovery of new compounds and biochemical targets that circumvent crossresistance patterns and give a fresh start in pesticide management to maintain effective control [1]. Any novel target is therefore a valuable contribution not only to science but also to human welfare. The $\gamma$-aminobutyric acid (GABA) receptor (GABA-R) is the target for many insecticides, acaricides, anthelmintics and rodenticides of widely varied structures [2-8]. The extracellular and transmembrane domains also have multiple targets for other antagonists, agonists and modulators of various types. There are two recent insecticide chemotypes added to this list, i.e. the isoxazolines and meta-diamides which do not appear to have target site cross resistance with any other type of insecticide and are therefore of special importance and the focus of this review (Fig 1; Table 1).

\section{GABA Receptor}

\subsection{Structure and function}

GABA is the principal inhibitory neurotransmitter in the insect and mammalian nervous systems [5-11]. Ionotropic GABA-Rs are ligand-gated chloride channels consisting of five heteromeric subunits in mammals (usually two $\alpha$ subunits. two $\beta$ subunits and an additional subunit) and presumably the homopentameric RDL subunit [12] in insects arranged around a central pore. The amino acid sequences and genomics are well characterized [10] and the individual subunits can be expressed in different combinations [13]. Each subunit has four transmembrane segments (M1, M2, M3 and M4) with both the $\mathrm{N}$ - and C- terminals located extracellularly. The receptor on binding to GABA changes conformation opening the pore allowing chloride anions to pass leading to inhibitory action.

\subsection{Target site models}

Most insect GABA-R studies involve Musca domestica or Drosophila melanogaster (Dm) head membranes or expressed RDL homopentamer receptor [6, 12, 14]. Mammalian brain membranes extensively used are rat, mouse and human with apparently very similar or identical results. The expressed mammalian receptor requires the $\beta_{3}$ subunit for high insecticide radioligand binding activity which is modulated for sensitivity and specificity by $\alpha$ and $\gamma$ subunits. The expressed $\alpha_{1} \beta_{3} \gamma_{2}$ receptor is typically used for binding assays and the $\alpha_{1} \beta_{2} \gamma_{2}$ for molecular modeling with respect to selective toxicity. The human expressed $\beta_{3}$ homopentamer is of special interest because it is similar in sensitivity and inhibitor specificity to the native housefly or RDL receptor $[13,15,16]$. The target site models are based on 1) mutants or sensitivity determinants in defining the relevant receptor locus, 2) the X-ray structure of the receptor or of a homologous anionic Cys-loop receptor, and 3) molecular dynamics to optimize the definition of ligand-binding site interactions. A large number of site-directed mutations have been examined for the $\beta_{3}$ homopentamer and RDL GABA-R to aid in locating the binding sites.

Although we reported a partial $\beta_{3}$ homopentamer model in 2006 [16], de novo generation of a new homology model was most prudent given the recent X-ray structures with high sequence homology including: PDB ID 2VL0, a ligand-gated ion channel from Erwina chrysanthemi [17]: 3RHW, a glutamate-gated chloride channel ( $\mathrm{GluCl})$ from Caenorhabditis elegans [18] in complex with ivermectin; and most recently $4 \mathrm{COF}$, a human $\mathrm{GABA}_{\mathrm{A}} \mathrm{R}-\beta_{3}$ homopentamer with benzamidine bound to the neurotransmitter site [11]. We built homology models of the Dm RDL 
(Uniprot P25123) using both 3RHW and 4COF as templates. Computational work presented here was done on the 3 RHW based model before $4 \mathrm{COF}$ was published. Preliminary results using the $4 \mathrm{COF}$ based model are presented in the Supplementary Information. The 3RHW template is presumed to be in the open pore state whereas the 4COF template is in the closed state. Models were built using both Prime (part of the Maestro Suite from Schrodinger) [19] and the SwissModel server [20-22]. Sequence alignment was based on BLAST with small manual adjustments. The M3/M4 intracellular connecting loop was replaced with 12 glycine residues based on other studies suggesting that a glycine rich loop gives a stable geometry [10, 23, 24]. Models were refined using both Prime and Macromodel and a consenus homology structure was developed from this series of steps. Molecular dynamics simulations were performed using Desmond [25] including both a full membrane model surrounding the transmembrane helices and a water box encompassing the entire pentameric homology model with membrane. Each of three ligands (fipronil, TETS, R-fluralaner) was individually placed in the pore of this homology model + membrane + water box and subjected to $24 \mathrm{~ns}$ of molecular dynamics simulation. An additional $24 \mathrm{~ns}$ molecular dynamics run was performed with no ligand in the pore, but with 5 ivermectin units in the transmembrane interstitial binding region. Additionally, we performed docking calculations using Glide [19]. The receptor for Glide calculations was derived from the fully mature molecular dynamics refined, ligand bound structures.

\section{First Generation Non-Competitive Antagonists}

\subsection{NCA-IA site}

\subsubsection{Structures}

The first generation or $20^{\text {th }}$ century GABAergic insecticides, designated here as noncompetitive antagonist (NCA) Type IA (NCA-IA) (Fig 1), consist of many major commercial compounds (Fig 2 and Supplementary Material Fig 1). The botanical picrotoxinin was reported in 1875 to control pest insects. The polychlorocycloalkanes (lindane and toxaphene) and cyclodienes (e.g. dieldrin and $\alpha$-endosulfan) were introduced in 1945-1961 and the phenylpyrazole fipronil in 1988. A large number and variety of heterocyclics including 4- $t$ butylbicyclophosphorothionate (TBPS) and 4'-ethynyl-4- $n$-propylbicycloorthobenzoate (EBOB) were examined in the author's laboratory in the 1980s [2-4]. NCA-IA binding assays first used the radioligand $\left[{ }^{3} \mathrm{H}\right]$ dihydropicrotoxinin [26-28] which was soon replaced by $\left[{ }^{35} \mathrm{~S}\right] \mathrm{TBPS}[29]$ and $\left[{ }^{3} \mathrm{H}\right]$ EBOB [30]. $\left[{ }^{3} \mathrm{H}\right] \alpha$-Endosulfan [31] and particularly $\left[{ }^{3} \mathrm{H}\right] \mathrm{BIDN}$ [32] proved to be the most useful of the polychlorocycloalkanes for this target. Photoaffinity probes have been identified $[33,34]$ but not used in structural assignment of the NCA-IA binding site.

\subsubsection{NCA action, resistance and binding sites}

The polychlorocycloalkanes, cyclodienes and fiproles are NCAs and inhibit the binding of diagnostic NCA-IA radioligands indicated above and inhibit GABA-induced neuroactivity and GABA-induced chloride flux [35-38] (Table 1). Resistant strains and mutants were particularly important in defining the NCA-IA target site. In a seminal study ffrench-Constant and colleagues [14] established that housefly resistance to dieldrin is attributable to a GABA-R A2'S mutation which was then found to confer low sensitivity of the binding site [39]. It was soon recognized that broad cross resistance to polychlorocycloalkanes was conferred by this A2'S mutation [40] but to varying degrees for dieldrin, $\alpha$-endosulfan, fipronil and other NCA-IA compounds. Site- 
directed mutagenesis, cysteine scanning and molecular modeling of the NCA-IA target established the importance of interactions with channel-lining residues A2', T6' and L9' [6, 7, 16, 41], a conclusion which is essentially unchanged when updated based on the docking positions for fipronil and EBOB (Fig 2) in our current models. Diazepam and phenobarbital are effective antidotes for NCA-IAs [42].

\subsection{NCA-IB site}

NCA-IB compounds were serendipitous discoveries in the late $20^{\text {th }}$ century (Fig. 1) as toxicants for mammals in studies on resins used in wool impregnation (TETS) [43], oxidation of phosphorothionates [42, 44, 45] and thermal degradation of phosphorus flame retardants [46]. TETS [47], TBPS [29] and its oxon analog (TBPO) [45, 48] are highly toxic to mammals (mouse ip $\mathrm{LD}_{50}$ values $0.03-0.3 \mathrm{mg} / \mathrm{kg}$ ) acting as convulsants and considered to be chemical threat agents $[49,50]$. They are small cage compounds (Type B or NCA-IB cage convulsants) with lower receptor potency relative to their toxicity than larger or more elongated compounds (NCA-IA, insecticides) [51]. TETS was developed and later banned as a rodenticide [50]. The NCA-IB target can be assayed with $\left[{ }^{35}\right.$ S]TBPS [52, 53] or $\left[{ }^{3} \mathrm{H}\right] \mathrm{EBOB}[30]$ for Musca and with $\left[{ }^{35}\right.$ S]TBPS or $\left[{ }^{14} \mathrm{C}\right]$ TETS for mammalian brain $[29,50]$. There is no cross resistance of NCA-IBs to dieldrin in RDL houseflies [54]. Molecular dynamics modeling with the human $\alpha_{1} \beta_{2} \gamma_{2}$ receptor positions TETS with TBPS deep in the channel in the 1' to 2' region [50] as also found here for the RDL GABA-R (Fig 2). [ ${ }^{35}$ S]TBPS binding in mammalian brain membranes is inhibited by GABA, fipronil and cyclodienes. The toxicity of NCA-IBs to Musca has a negative temperature coefficient in contrast to the positive coefficient for more elongated (Type A) compounds [55]. Their toxicity to mice is ameliorated by phenobarbital and diazepam [42]. The chemical threat status of TETS focused attention on candidate antidotal agents with special attention to diazepam, midazolam, propofol, allopreganolone and the NMDA antagonist MK-801 [50, 56].

\section{Second Generation Non-Competitive Antagonists: NCA-II Site}

\subsection{Structures}

The last 5 years has been an exciting time in studies of the GABAergic insecticides with the announcement of two second generation or $21^{\text {st }}$ century chemotypes acting as NCAs and designated here as NCA-II (Figs 1 and 3). The research in every case started from phthalic and anthranilic diamides, which are activators of insect ryanodine receptors, and ended up with insecticides of a completely different mode of action. Researchers at Nissan Chemical Industries in Japan and DuPont in the United States discovered insecticidal isoxazolines optimized to fluralaner (flu) and afoxolaner, respectively, as current commercial compounds. Scientists at Mitsui Chemicals Agro in Japan discovered the meta-diamides including benzamidophenylbenzamides (BPBs).

\subsection{NCA action}

Several types of evidence establish that isoxazolines [57-66] and meta-diamides (including mDA-7 [24, 67] and BPB-1 [68]) are NCAs but at a different high affinity site(s) than those for compounds acting at the NCA-IA, NCA-IB and AVE targets (Table 1). There is subnanomolar $\left[{ }^{3} \mathrm{H}\right] \mathrm{EBOB} \mathrm{IC}_{50}$ for some NCA-II compounds and apparent $\mathrm{K}_{\mathrm{d}}$ for NCA-II radioligands [ $\left.{ }^{3} \mathrm{H}\right] \mathrm{flu}$ and $\left[{ }^{3} \mathrm{H}\right] \mathrm{BPB}-1$ for a high affinity site(s) but with a portion of lower affinity sites. [ $\left.{ }^{3} \mathrm{H}\right] \mathrm{BPB}-1$ binding is allosterically inhibited by micromolar GABA. Isoxazoline and meta-diamide chemotypes inhibit GABA-induced currents in housefly GABA-Rs expressed in Xenopus 
oocytes but are less potent or failed to inhibit L-glutamate-induced currents in inhibitory Lglutamate receptors. Fipronil is a weak inhibitor of $\left[{ }^{3} \mathrm{H}\right]$ flu binding but strongly stimulates $\left[{ }^{3} \mathrm{H}\right] \mathrm{BPB}-1$ binding. Ave is a potent inhibitor of both $\left[{ }^{3} \mathrm{H}\right]$ flu and $\left[{ }^{3} \mathrm{H}\right] \mathrm{BPB}-1$ specific binding.

\subsection{Resistance and NCA-II binding site}

There is no NCA-II target site cross-resistance with the NCA-IA insecticides but three mutations [M3/G336M (homologous to G319M in Spodoptera littoralis SL-RDL), M1/I277F and M1/L281C] in the RDL GABA-R reduce its sensitivity to meta-diamides [24, 67]. Homology modeling herein showing a clean overlay of isoxazolines and meta-diamides suggests the NCA-II localization is in the pore T9' to S15' region (Fig 3), an area which is adjacent to the AVE M2/M3, M1 interstitial subunit region. The mutations mentioned above occur in this interstitial subunit area and thus might change the shape of the pore, affecting meta-diamide binding. It has also been suggested that the NCA-II target site is directly in this interstitial region, a new location perhaps bridging the pore and the AVE site [24]. Our modeling does not eliminate the possibility of this alternate NCA-II site (Supplementary Material Fig 3). It is conceivable that the NCA-II enters in the pore and then migrates to the interstitial region or vice versa. As further speculation perhaps the meta-diamides trigger closing or stabilize the closed state. The NCA-II site(s) defined by Musca binding assays with $\left[{ }^{3} \mathrm{H}\right] \mathrm{flu}[58,66]$ and $\left[{ }^{3} \mathrm{H}\right] \mathrm{BPB}-1$ [68] is probably the same target for isoxazolines and meta-diamides [66].

\section{Allosteric Modulator (AVE)}

The macrocyclic lactone ave (Fig 4) was first used as an antiparasitic drug in 1981 and as an agricultural pesticide in 1985 [69] and several analogs and derivatives (such as emamectin benzoate, lepimectin and milbemectin) are also important commercial compounds [1]. Ivermectin was the essential agent in greatly reducing the incidence of river blindness in millions of people by controlling the schistisome vector [69]. Ave is a positive allosteric modulator of several ligand-gated channels including GABA- and glutamate-gated chloride channels and the $\alpha 7$-nicotinic receptor [70-73]. The GABA-R target for ave is designated here as AVE. $\left[{ }^{3} \mathrm{H}\right]$ Ave is very effective as a radioligand for both insects and mammals in defining AVE action [55, 73]. $\left[{ }^{3} \mathrm{H}\right]$ Ave binding in Musca is not inhibited by GABA, fipronil or cyclodienes but is by flu. The $C$. elegans glutamate-gated chloride channel was important in structural definition of the RDL AVE site although a muscle glutamate receptor may be important in contributing to or the cause of the toxicity [69-75]. Decreased binding is conferred by in silico mutations to A/Q6 and B1/S58 [75]. The ave binding site appears to be in an interstitial region between M2/M3 of one subunit and M1 of an adjacent subunit, a site which is proximal to the L9' to S16' pore region. Interactions modulate chloride flux at low ave concentrations and block the channel at high levels.

\section{Four Distinct Binding Sites}

\subsection{Radioligand binding assays}

Radioligand binding studies play an important role in defining GABAergic pesticide action.The best radioligand for each binding site is the pesticide itself or an arguably-relevant analog, highly potent (i.e. high affinity and percent specific binding) and available or attainable at adequate specific activity (normally ${ }^{3} \mathrm{H},{ }^{32} \mathrm{P}$ or ${ }^{35} \mathrm{~S}$ analyzed by liquid scintillation counting but recently ${ }^{14} \mathrm{C}$ quantified by accelerator mass spectroscopy [50]). The radioligands considered here for the four GABAergic targets (Table 1) meet most or all of these requirements. The receptor source must be relevant (nerve, cell, membrane or expressed GABA-R) and readily available 
(culture or purchase) as the sensitive native material perhaps supplemented by less sensitive versions from selected resistant strains or from expressed receptor with low sensitivity from sitedirected mutagenesis.

\subsection{Toxicological relevance}

The relevance of a target site assay involving radioligand binding or physiological response (e.g. ${ }^{36}$ chloride uptake or GABA induced signals) is normally established by structure-activity relationships in which the in vitro potency for a series of compounds should be correlated with or predictive of their toxicity (using a CYP450-inhibiting synergist when appropriate). This structure-activity relationship criterion is met for NCA-IA and NCA-IB compounds assayed as either $\left[{ }^{35} \mathrm{~S}\right]$ TBPS binding (Fig. 5A) or ${ }^{36}$ chloride uptake (Fig. 5B) in mammalian brain membranes. Inhibition of housefly membrane NCA-IB $\left[{ }^{35} \mathrm{~S}\right] \mathrm{TBPS}$ binding by a series of cyclodiene insecticides also follows the same potency trend as their injected toxicity to houseflies [52]. The most extensive data set is for NCA-IA compounds of many chemotypes assayed with housefly head membranes and toxicity to houseflies with piperonyl butoxide synergist clearly establishing a target assay-toxicity correlation involving widely varied structures (Fig. 5C) [35]. The same housefly systems with $\left[{ }^{3} \mathrm{H}\right]$ ave and ave analogs also validate the relevance of assays of the AVE site (Fig. 5D) [55, 76]. The data sets are smaller and of different types for the NCA-II compounds with the isoxazolines based on binding assays and GABA response (Fig. 5E and 5F) [61, 66] and the BPBs on radioligand results [68]. Despite the diversity of in vitro assays and toxicity criteria it is clear that the targets being measured are relevant to the toxicity.

\subsection{Overlapping and coupled targets}

The proposed relationship of these four binding sites in the Dm RDL GABA-R (Fig 6 and Supplementary Material Figs 4 and 5) indicates the overlapping and coupled nature of the targets. The pesticides differ greatly in size and physiochemical properties. The molecular surface area and solvent accessible volume of the ligands increase in the order of those for NCA-IB < NCAIA < NCA-II < ave (Table 1, Supplementary Material Table 1 and Fig. 2). Their extended length in the GABA-R pore of the illustrated model is 5-8 $\AA$ for NCA-IB, 12-13 $\AA$ for NCA-IA and 16$20 \AA$ for NCA-II (Table 1). The number of halogens for compounds illustrated here is zero for NCA-IB and AVE, 0-6 chlorines and 0-6 fluorines for NCA-IA, and 0-2 chlorines or bromines and 6-11 fluorines for NCA-II. $\left[{ }^{3} \mathrm{H}\right] \mathrm{EBOB}$ specific binding in Musca is strongly and fully inhibited by NCA-IA and NCA-IB compounds but only partially by NCA-II and ave insecticides. The NCA-IB $\left[{ }^{35} \mathrm{~S}\right]$ TBPS or $\left[{ }^{14} \mathrm{C}\right]$ TETS binding site interactions appear to follow the same pattern for NCA-IA, NCA-IB and ave compounds. $\left[{ }^{3} \mathrm{H}\right] \mathrm{Flu}$ binding in $\mathrm{Musca}$ is insensitive or poorly sensitive to NCA-IA compounds but very sensitive to aves. In agreement, $\left[{ }^{3} \mathrm{H}\right]$ ave binding is sensitive to NCA-II flu but NCA-IA and NCA-IB compounds are not inhibitors [59, 66] (Table 1). It is not known to what extent if any these binding site interactions for different GABAergic agents noted here in vitro might be applicable to toxicity changes in vivo.

\subsection{Selective toxicity}

GABA-R target site sensitivity and specificity play important roles in selective toxicity between pest strains, insect species and non-target organisms. The receptor preparations considered here are generally mammalian brain membranes and expressed GABA $\mathrm{R} \beta_{3}$ homopentamer compared with Musca and Dm head membranes and expressed RDL GABA-R. NCA-IA compounds are only moderately selective between insects and mammals and their 
GABA-Rs although lindane is somewhat more selective than the cyclodienes [13]. The selectivity is improved with fiproles [77] optimized from a great variety of insecticidal heterocycles $[4,7]$. NCA-IB compounds are highly toxic cage convulsants to mammals leading to their use as rodenticides and importance as chemical threat agents. The low potency of NCAIIs in mammalian brain and $\beta_{3}$ homopentamer $\mathrm{GABA}_{\mathrm{A}} \mathrm{R}$ binding assays $[58,66]$ and use in animal health considered later indicate favorable selectivity but little information is available on these new NCAs used directly as radioligands with mammalian GABA-Rs. There is extensive human toxicology data from the use of ivermectin for schistosomiasis control and toxicity problems are largely avoided by the low doses required for human therapy and when employed as insecticides for pets and farm animals [69].

\subsection{Cross resistance}

Resistance following pesticide selection of pest populations or site-directed mutagenesis is indicated when the strain survives a normally lethal dose or has reduced sensitivity in neuroactivity, chloride flux or binding assays (Table 1). Genomic definition of the mutations conferring resistance then allows monitoring their incidence in field populations [78]. The Insecticide Resistance Action Committee (IRAC) [1] classifies GABAergic insecticides on the basis of recommendations for use to avoid cross-resistance into Categories $2 \mathrm{~A}$ (organochlorines and cyclodienes, i.e. endosulfan and chlordane), $\mathbf{2 B}$ (phenylpyrazoles or fiproles, i.e. fipronil and ethiprole) and $\mathbf{6}$ (macrocyclics such as abamectin, emamectin benzoate, lepimectin, and milbemectin). The new isoxazolines and meta-diamides for now have no IRAC classification. These NCA-II chemotypes are not cross-resistant with categories $\mathbf{2 A}, \mathbf{2 B}$ and $\mathbf{6}$ (i.e. compounds acting at the NCA-IA and AVE targets) which therefore makes them of special interest.

\section{Prospects}

The prospects for GABAergic pesticides can be projected from the rate at which new compounds have been introduced (Fig 1) and the amounts used. More than three billion pounds of NCA-IA insecticides were used in the past seven decades. There was no target site crossresistance of the NCA-IA compounds to DDT, organophosphate or any other major insecticide chemotypes. Use of NCA-IAs drastically declined in the late $20^{\text {th }}$ century with problems of resistance, persistence and environmental toxicology. Their effectiveness was due in part to their long persistence but this ultimately proved to be a major reason for their demise. The Stockholm Convention on Persistent Organic Pollutants [79] in 2001 banned most organochlorine and cyclodiene insecticides (NCA-IA), reducing but not eliminating their use. However the GABAergic insecticides are still very important with the 2012 world end use value for fipronil of $\$ 688$ million and for abamectin of $\$ 938$ million [80]. Insecticide target rankings in 2012 world sales were led by the nicotinic receptor $(37 \%)$ then the sodium channel and GABA-R (each 16$17 \%$ ) and the ryanodine receptor and acetylcholinesterase (each 10-11\%) with 9\% other targets [81]. A 2012 compilation considering the chronology and numbers for introduction of the current insecticides gave the GABA-R targeting compounds as only $1.7 \%$ of the total with half of them introduced by 1955 [81]. Newly-introduced GABAergic insecticides are flu and afoxolaner used for flea and tick control on cats and dogs [58, 62-65]. There are also important crop pests highly sensitive to NCA-IIs [24, 60, 82] indicating possible expanded use on optimization. Just as NCA-IA was recognized over time as the target for an increasing variety of insecticides [16] so the NCA-II target may ultimately be the binding site for more than the two chemotypes considered here. The NCA-IIs appear to have fewer limitations of target site cross-resistance and selective toxicity. No detailed reports are available yet on the metabolism, persistence or 
environmental toxicology of the new NCA-II insecticides but for now there is optimism that they can at least partially replace the NCA-IAs as safe and effective pest control agents.

\section{Associated Content}

\section{Author Information}

Corresponding Author

*Phone: 510-642-5424 Fax: 510-642-6497 Email: ectl@berkeley.edu

\section{Funding}

KAD acknowledges NSF grant CHE-0840505 for support of the Molecular Graphics and Computation Facility.

\section{Acknowledgements}

We thank Madhur Garg, Breanna Ford and Liane Kuo for outstanding contributions in literature research, discussions and manuscript preparation.

\section{References}

[1] IRAC: Insecticide Resistance Action Committee. IRAC MoA Classification Scheme. 2014. Retrieved from http://www.irac-online.org/documents/moa-classification/?ext=pdf.

[2] Casida JE. Insecticide action at the GABA-gated chloride channel: recognition, progress, and prospects. Arch. Insect Biochem. Physiol., 1993, 22: 13-23.

[3] Hawkinson JE, Casida JE. Insecticide binding sites on $\gamma$-aminobutyric acid receptors of insects and mammals. In Pest Control with Enhanced Environmental Safety; Duke SO, Menn JJ, Plimmer JR Eds.; ACS Symposium Series, American Chemical Society, Washington DC, 1993, 524:126-143.

[4] Casida, JE, Pulman, DA. Recent advances on heterocyclic insecticides acting as GABA antagonists. In Advances in the Chemistry of Insect Control III; Special Publications of the Royal Society of Chemistry 1994, 147:36-51.

[5] Ozoe Y, Akamatsu M. Non-competitive GABA antagonists: probing the mechanisms of their selectivity for insect versus mammalian receptors. Pest Manag. Sci. 2001, 57:923931.

[6] Buckingham SD, Biggin PC, Sattelle BM, Brown LA, Sattelle DB. Insect GABA receptors: splicing, editing, and targeting by antiparasitics and insecticides. Mol. Pharmacol. 2005, 68:942-951.

[7] Ozoe Y, Takeda M, Matsuda K. $\gamma$-Aminobutyric acid receptors: a rationale for developing selective insect pest control chemicals. In: Ishaaya I, Horowitz AR Eds.; Biorational Control of Arthropod Pests, Springer, New York, 2009; pp 131-162.

[8] Ozoe Y. $\gamma$-Aminobutyrate- and glutamate-gated chloride channels as targets of insecticides, Adv. Insect Physiol. 2013, 44:211-286.

[9] Sattelle DB. GABA receptors of insects. Adv. Insect Physiol. 1990. 22:1-113. 
[10] Olsen RW, Sieghart W. International Union of Pharmacology. LXX. Subtypes of $\gamma$ aminobutyric $\mathrm{acid}_{\mathrm{A}}$ receptors: classification on the basis of subunit composition, pharmacology, and function. Update. Pharmacol Rev 2008, 60:243-260.

[11] Miller PS, Aricescu AR. Crystal structure of human GABAA receptor. Nature 2014, doi: 10.1038/nature13293.

[12] McGonigle I, Lummis SCR. RDL receptors. Biochem. Soc. Trans. 2009, 37:1404-1406.

[13] Ratra GS, Casida JE. GABA receptor subunit composition relative to insecticide potency and selectivity. Toxicol. Lett. 2001, 122:215-222.

[14] ffrench-Constant RH, Steichen JC, Rocheleau TA, Aronstein K, Roush RT. A singleamino acid substitution in $\gamma$-aminobutyric acid subtype A receptor locus is associated with cyclodiene insecticide resistance in Drosophila populations. Proc. Natl. Acad. Sci. 1993, 90:1957-1961.

[15] Ratra GS, Kamita SG, Casida JE. Role of human $\mathrm{GABA}_{\mathrm{A}}$ receptor $\beta 3$ subunit in insecticide toxicity. Toxicol. Appl. Pharm. 2001, 172:233-240.

[16] Chen L, Durkin KA, Casida JE. Structural model for $\gamma$-aminobutyric acid receptor noncompetitive antagonist binding: widely diverse structures fit the same site. Proc. Natl. Acad. Sci. 2006, 103:5185-5190.

[17] Hilf RJC, Dutzler R. X-ray structure of a prokaryotic pentameric ligand-gated ion channel. Nature. 2008, 452:375-379.

[18] Gouaux E, Hibbs RE. Principles of activation and permeation in an anion-selective cysloop receptor. Nature. 2011, 474:54-60.

[19] Prime 3.6, MacroModel 10.4, Glide 6.3, Schrödinger, LLC, New York, NY, 2014.

[20] Arnold K, Bordoli L, Kopp J, Schwede T. The SWISS-MODEL workspace: a web-based environment for protein structure homology modelling. Bioinformatics. 2006, 22:195201.

[21] Bordoli L, Kiefer F, Arnold K, Benkert P, Battey J, Schwede T. Protein structure homology modeling using SWISS-MODEL workspace. Nature Protocols. 2009, 4:1-13.

[22] Biasini M, Bienert S, Waterhouse A, Arnold K, Studer G, Schmidt T, Kiefer F, Cassarino TG, Bertoni M, Bordoli L, Schwede T. SWISS-MODEL: modelling protein tertiary and quaternary structure using evolutionary information. Nucleic Acids Res. 2014, 42(Web server issue):W252-258.

[23] Liu HL, Shu YC, Wu, YH. Molecular dynamics simulations to determine the optimal loop length in the helix-loop-helix motif. J. Biomol. Struct. Dyn. 2003, 20:741-745.

[24] Nakao T, Banba S, Nomura M, Hirase K. Meta-diamide insecticides acting on distinct sites of RDL GABA receptor from those for conventional noncompetitive antagonists. Insect Biochem. Mol. Biol. 2013, 43:366-375.

[25] Bowers KJ, Chow E, Xu H, Dror RO, Eastwood MP, Gregersen BA, Klepeis JL, Kolossvary I, Moraes MA, Sacerdoti FD, Salmon JK, Shan Y, Shaw DE. Scalable Algorithms for Molecular Dynamics Simulations on Commodity Clusters. Proceedings of the ACM/IEEE Conference on Supercomputing (SC06), Tampa, Florida, 2006, 
November 11-17.

[26] Ticku MK, Ban M, Olsen RW. Binding of $\left[{ }^{3} \mathrm{H}\right] \alpha$-dihydropicrotoxinin, a $\gamma$-aminobutyric acid synaptic antagonist, to rat brain membranes. Mol Pharmacol. 1978. 14:391-402

[27] Ghiasuddin SM, Matsumura F. Inhibition of gamma-aminobutyric acid (GABA)-induced chloride uptake by gamma-BHC and heptachlor epoxide. Comp Biochem Physiol. Part C, Comp. Pharmacol. 1982, 73:141-144.

[28] Matsumura F, Ghiasuddin SM. Evidence for similarities between cyclodiene type insecticides and picrotoxinin in their action mechanisms. J Environ Sci Health B. 1983;18:1-14.

[29] Squires RF, Casida JE, Richardson M, Saederup E. $\left[{ }^{35} \mathrm{~S}\right] t$-Butylbicyclophosphorothionate binds with high affinity to brain-specific sites coupled to $\gamma$-aminobutyric acid-A and ion recognition sites. Mol. Pharmacol. 1983. 23:326-336.

[30] Cole LM, Casida JE. GABA-gated chloride channel: binding site for 4'-ethynyl-4- $n$-[2.3$\left.{ }^{3} \mathrm{H}_{2}\right]$ propylbicycloorthobenzoate $\left(\left[{ }^{3} \mathrm{H}\right] \mathrm{EBOB}\right)$ in vertebrate brain and insect head. Pestic. Biochem. Physiol 1992, 44:1-8.

[31] Cole LM, Saleh MA, Casida JE. House fly head GABA-gated chloride channel: $\left[{ }^{3} \mathrm{H}\right] \alpha-$ endosulfan binding in relation to polychlorocycloalkane insecticide action. Pestic. Sci. 1994, 42:59-63.

[32] Rauh JJ, Benner E, Schnee ME, Cordova D, Holyoke CW, Howard MH, Bai D, Buckingham SD, Hutton ML, Hamon A, Roush RT, Sattelle DB. Effects of $\left[{ }^{3} \mathrm{H}\right]-\mathrm{BIDN}$, a novel bicyclic dinitrile radioligand for GABA-gated chloride channels of insects and vertebrates. Br. J. Pharmacol. 1997, 121:1496-1505.

[33] Sirisoma NS, Ratra GS, Tomizawa M, Casida JE. Fipronil-based photoaffinity probe for Drosophila and human $\beta 3$ GABA receptors. Bioorg. Med. Chem. Lett. 2001, 11:29792981.

[34] Sammelson RE, Casida JE. Synthesis of a tritium-labeled, fipronil-based, highly potent, photoaffinity probe for the GABA receptor. J. Org. Chem. 2003. 68:8075-8079.

[35] Deng Y, Palmer CJ, Casida JE. House fly brain $\gamma$-aminobutyric acid-gated chloride channel: target for multiple classes of insecticides. Pestic. Biochem. Physiol. 1991, 41:60-65.

[36] Cole LM, Nicholson RA, Casida JE. Action of phenylpyrazole insecticides at the GABAgated chloride channel. Pestic. Biochem. Physiol. 1993. 46:47-54

[37] Huang J, Casida JE. Characterization of $\left[{ }^{3} \mathrm{H}\right]$ ethynylbicycloorthobenzoate $\left(\left[{ }^{3} \mathrm{H}\right] \mathrm{EBOB}\right)$ binding and the action of insecticides on the $\gamma$-aminobutyric acid-gated chloride channel of cultured cerebellar granule neurons. J. Pharmacol. Exp. Ther. 1996, 279:1191-1196.

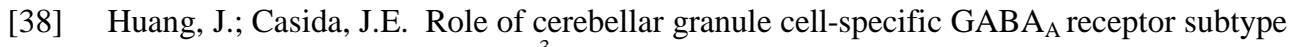
in the differential sensitivity of $\left[{ }^{3} \mathrm{H}\right]$ ethynylbicycloorthobenzoate binding to GABA mimetics. Neurosci. Lett. 1997, 225:85-88.

[39] Cole LM, Roush RT, Casida JE. Drosophila GABA-gated chloride channel: modified $\left[{ }^{3} \mathrm{H}\right] \mathrm{EBOB}$ binding site associated with Ala $\rightarrow$ Ser or Gly mutants of $R d l$ subunit. Life 
Sci. 1995, 56:757-765.

[40] ffrench-Constant RH, Anthony N, Aronstein K, Rocheleau TA, Stilwell G. Cyclodiene insecticide resistance: from molecular to population genetics. Annu Rev Entomol 2000, 48:449-466.

[41] Hisano K, Ozoe F, Huang J, Kong X, Ozoe Y.The channel-lining 6' amino acid in the second membrane-spanning region of ionotropic GABA receptors has more profound effects on 4'-ethynyl-4- $n$-propylbicycloorthobenzoate binding than the 2' amino acid. Invert. Neurosci. 2007, 7:39-46.

[42] Casida JE, Eto M, Moscioni AD, Engel JL, Milbrath DS, Verkade JG. Structure-toxicity relationships of 2,6,7-trioxabicyclo[2.2.2] octanes and related compounds. Toxicol Appl Pharmacol 1976. 36:261-279.

[43] Hecht G, Henecka H. Über ein hochtoxiches kondensationsprodukt von sulfamid und formaldehyd. Angew Chem 1949, 61:365-366.

[44] Bellet EM, Casida JE. Bicyclic phosphorus esters: high toxicity without cholinesterase inhibition. Science 1973, 182:1135-1136

[45] Milbrath DS, Engel JL, Verkade JG, Casida JE. Structure-toxicity relationships of 1substituted-4-alkyl-2,6,7-trioxabicyclo[2.2.2]octanes. Toxicol. Appl. Pharmacol. 1979, 47:287-293.

[46] Petajan JH, Voorhees KJ, Packham SC, Baldwin RC, Einhorn IN, Grunnet ML, Dinger BG, Birky MM. Extreme toxicity from combustion products of a fire-retarded polyurethane foam. Science 1975. 187: 742-744.

[47] Esser T, Karu AE, Toia RF, Casida JE. Recognition of tetramethylenedisulfotetramine and related sulfamides by the brain GABA-gated chloride channel and a cyclodienesensitive monoclonal antibody. Chem. Res. Toxicol 1991, 4:162-167.

[48] Eto M, Ozoe Y, Fujita T, Casida JE. Significance of branched bridge-head substituent in toxicity of bicyclic phosphate esters. Agric. Biol. Chem. 1976, 40:2113-2115.

[49] Ellison DH. Bicyclophosphate convulsants. Chapter 6 in "Handbook of Chemical and Biological Warfare Agents." $2^{\text {nd }}$ Ed. CRC Press: Boca Raton, FL. 2008; pp 221-230.

[50] Zhao C, Hwang SH, Buchholz BA, Carpenter TS, Lightstone FC, Yang J, Hammock BD, Casida JE. GABA $\mathrm{A}$ receptor target of tetramethylenedisulfotetramine. Proc. Natl. Acad. Sci. 2014. 111:8607-8612.

[51] Palmer CJ, Casida JE. Two types of cage convulsant action at the GABA-gated chloride channel. Toxicol. Lett. 1998, 42:117-122.

[52] Cohen E, Casida JE. Effects of insecticides and GABAergic agents on a house fly $\left[{ }^{35} \mathrm{~S}\right] t$ butylbicyclophosphorothionate binding site. Pestic. Biochem. Physiol 1986. 25:63-73.

[53] Olsen RW, Szamraj O, Miller T. $t-\left[{ }^{35}\right.$ S]Butylbicyclophosphorothionate binding sites in invertebrate tissues. J Neurochem. 1989, 52:1311-1318.

[54] Deng Y, Palmer CJ, Casida JE. House fly head GABA-gated chloride channel: four putative insecticide binding sites differentiated by $\left[{ }^{3} \mathrm{H}\right] \mathrm{EBOB}$ and $\left[{ }^{35} \mathrm{~S}\right] \mathrm{TBPS}$. Pestic. Biochem. Physiol. 1993, 47:98-112. 
[55] Deng Y, Casida JE. House fly head GABA-gated chloride channel: toxicologically relevant binding site for avermectins coupled to site for ethynylbicycloorthobenzoate. Pestic. Biochem. Physiol. 1992, 43:116-122.

[56] Shakarjian MP, Velíšková J, Stanton PK, Velíšek L. Differential antagonism of tetramethylenedisulfotetramine-induced seizures by agents acting at NMDA and GABA receptors. Toxicol. Appl. Pharmacol. 2012, 265:113-121.

[57] Mita, T.; Kikuchi, T.; Mizukoshi, T.; Yaosaka, M.; Komoda, M. Isoxazoline-substituted benzamide compound and noxious organism control agent, WO 2005-085126, JP 2007308471.

[58] Ozoe Y, Asahi M, Ozoe F, Nakahira K, Mita T. The antiparasitic isoxazoline A1443 is a potent blocker of insect ligand-gated chloride channels. Biochem. Biophys. Res. Commun. 2010, 391:744-749.

[59] García-Reynaga P, Zhao C, Sarpong R, Casida JE. New GABA/glutamate receptor target for $\left[{ }^{3} \mathrm{H}\right]$ isoxazoline insecticide. Chem. Res. Toxicol. 2013, 26:514-516.

[60] Lahm, G. P.; Shoop, W. L; Xu, M. Isoxazolines for controlling invertebrate pests. U.S. Patent 8231888. 2012, Application:13/156,653.

[61] Lahm GP, Cordova D, Barry JD, Pahutski TF, Smith BK, Long JK, Benner EA, Holyoke CW, Joraski K, Xu M, Schroeder ME, Wagerle T, Mahaffey MJ, Smith RM, Tong M-H. 4-Azolylphenyl isoxazoline insecticides acting at the GABA gated chloride channel. Bioorg. Med. Chem. Lett. 2013, 23:3001-3006.

[62] Shoop WL, Hartline EJ, Gould BR, Waddell ME, McDowell RG, Kinney JB, Lahm GP, Long JK, Xu M, Wagerle T, Jones GS, Dietrich RF, Cordova D, Schroeder ME, Rhoades DF, Benner EA, Confalone PN. Discovery and mode of action of afoxolaner, a new isoxazoline parasiticide for dogs. Vet. Parasitol. 2014. 201:179-189.

[63] Kilp S, Ramirez D, Allan MJ, Roepke RKA, Nuernberger MC. Pharmacokinetics of fluralaner in dogs following a single oral or intravenous administration. Parasites \& Vectors 2014, 7:85.

[64] Asahi M, Kobayashi M, Matsui H, Nakahira K. Differential mechanisms of action of the novel $\gamma$-aminobutyric acid receptor antagonist ectoparasiticides fluralaner (A1443) and fipronil. Pest Manag. Sci. 2014, doi: 10.1002/ps.3768.

[65] Gassel M, Wolf C, Noack S, Williams H, Ilg T. The novel isoxazoline ectoparasiticide fluralaner: selective inhibition of arthropod $\gamma$-aminobutyric acid- and L-glutamate-gated chloride channels and insecticidal/acaricidal activity. Insect Biochem. Mol. Biol. 2014, 45:111-124.

[66] Zhao C, Casida JE. Insect $\gamma$-aminobutyric acid receptors and isoxazoline insecticides: toxicological profiles relative to the binding sites of $\left[{ }^{3} \mathrm{H}\right]$ fluralaner, $\left[{ }^{3} \mathrm{H}\right]-4$ '-ethynyl-4- $n$ propylbicycloorthobenzoate, and $\left[{ }^{3} \mathrm{H}\right]$ avermectin. J Agric. Food Chem. 2014, 45:111124.

[67] Nakao T, Hirase K. A comparison of the modes of action of novel meta-diamide insecticides and conventional noncompetitive antagonists on the Spodoptera litura RDL GABA receptor. J. Pestic. Sci. 2013. 38:123-128. 
[68] Ozoe Y, Kita T, Ozoe F, Nakao T, Sato K, Hirase K. Insecticidal 3-benzamido- $N$ phenylbenzamides specifically bind with high affinity to a novel allosteric site in housefly GABA receptors. Pestic. Biochem. Physiol. 2013, 107:285-292.

[69] Campbell WC., Ed. Ivermectin and Abamectin, 363 pp. Springer-Verlag, New York, 1989.

[70] Lynagh T, Lynch JW. Molecular mechanisms of Cys-loop ion channel receptor modulation by ivermectin. Frontiers in Mol. Neurosci. 2012, 5:1-11.

[71] Lees K, Musgaard M, Suwanmanee S, Buckingham SD, Biggin P, Sattelle D. Actions of agonists, fipronil and ivermectin on the predominant in vivo splice and edit variant $\left(\mathrm{RDL}_{\mathrm{bd}}, \mathrm{I} / \mathrm{V}\right)$ of the Drosophila GABA receptor expressed in Xenopus laevis oocytes. PLoS ONE 2014, 9(5):e97468. doi: 10.1371/journal.pone.0097468.

[72] Zemkova H, Tvrdonova V, Bhattacharya A, Jindrichova M. Allosteric modulation of ligand gated ion channels by ivermectin. Physiol. Res. 2014, 63(Suppl.1):S215-S224.

[73] Huang J, Casida JE. Avermectin $B_{1 a}$ binds to high- and low-affinity sites with dual effects on the $\gamma$-aminobutyric acid-gated chloride channel in cultured cerebellar granule neurons. J. Pharmacol. Exp. Ther. 1997, 281:261-266.

[74] Wolstenholme JA. Ion channels and receptors as targets for the control of parasitic nematodes. Int. J. Parasitol. Drugs Drug Resist. 2011, 1:2-13.

[75] Hao M, Wang Q, Ma Q, Zhao J, Hou W, Chen L. Molecular characterization of avermectin that bind to Rdl $\beta 5$ GABA receptors of house fly. Advanced Materials Research 2013, 699:753-758.

[76] Deng Y. Insecticide binding sites in the house fly head $\gamma$-aminobutyric acid gated chloride-channel complex. In Molecular Action of Insecticides on Ion Channels; Clark JM, Ed.; American Chemical Society: ACS Symposium Series. 1995, 591:230-250.

[77] Hainzl D, Cole LM, Casida JE. Mechanisms for selective toxicity of fipronil insecticide and its sulfone metabolite and desulfinyl photoproduct. Chem. Res. Toxicol. 1998, 11:1529-1535.

[78] ffrench-Constant RH. The molecular genetics of insecticide resistance. Genetics. 2013, 194:807-815.

[79] United Nations Environment Programme. Stockholm Convention on Persistent Organic Pollutants. 2001. 2256 UNTS 119; 40 ILM 532.

[80] Agranova.co.uk. Data provided by T.C. Sparks.

[81] Casida JE, Durkin KA. Anticholinesterase insecticide retrospective. Chem. Biol. Interact. 2013, 203: 221-225.

[82] Yoshida, K.; Wakita, T.; Katsuta, H.; Kai, A.; Chiba, Y.; Takahashi, K.; Kato, H.; Kawahara, N.; Nomura, M.; Daido, H.; Maki, J.; Banba, S. Amide derivatives, process for preparation thereof and use thereof as insecticide. U.S. Patent 8563736. 2013, Application: 13/427,176. 


\section{Figure Legends:}

542 Figure 1. Chronology of GABAergic noncompetitive antagonist and allosteric modulator pesticides ${ }^{1}$

Figure 2. First generation non-competitive antagonists (NCA-I) showing example radioligands (asterisks indicate labeling positions) and proposed $\mathrm{Dm}$ RDL GABA-R binding sites (homology model based on 3RHW) for NCA-IA compounds (fipronil and EBOB) and NCA-IB compounds (TBPS and TETS). Four of the 5 individual M2 transmembrane pore helices are shown in the binding vicinity. One M2 helix has not been displayed to provide a view into the pore.

Figure 3. Second generation isoxazoline and meta-diamide non-competitive antagonists (NCA-II) and their proposed Dm RDL GABA-R binding sites (homology model based on 3RHW) displayed with single M2 transmembrane pore helix ( 1 of $5 \mathrm{M} 2$ helices in the channel pore). Asterisks indicate ${ }^{3} \mathrm{H}$ labeling positions of radioligands. Afoxolaner is the fluralaner analog with $\mathrm{CF}_{3}$ replacing one $\mathrm{Cl}$ and naphthyl replacing tolyl. Meta-diamide BPB-1 (68) is also referred to as mDA-1 (67)

Figure 4. Allosteric modulator ave showing radioligand $\left[{ }^{3} \mathrm{H}\right]$ avermectin $\mathrm{B}_{1 \mathrm{a}}$ and $D m$ RDL GABA-R binding sites (homology model based on $3 \mathrm{RHW}$ ). Abamectin is avermectin $\mathrm{B}_{1 \mathrm{a}}$ (docking position illustrated in cyan) and $\mathrm{B}_{1 \mathrm{~b}}$ (methyl replaces ethyl substituent). Ivermectin is 22,23-dihydroavermectin.

Figure 5. Correlation for GABAergic agents as inhibitors of GABA-R radioligand binding or GABA response and toxicity.

A. NCA-IA insecticides and NCA-IB cage convulsants as inhibitors of $\left[{ }^{35}\right.$ S $]$ TBPS binding in rat brain membranes and ip $\mathrm{LD}_{50}$ in mice. NCA-IA: $\mathrm{r}=0.77, \mathrm{n}=60$; NCA-IB: $\mathrm{r}=0.96, \mathrm{n}=15$. Adapted from reference 51 .

B. NCA-IA insecticides and NCA-IB cage convulsants as inhibitors of ${ }^{36}$ chloride uptake in rat brain membranes and ip $\mathrm{LD}_{50}$ in mice. NCA-IA: $\mathrm{r}=0.90, \mathrm{n}=15$; NCA-IB: $\mathrm{r}=0.92, \mathrm{n}=8$. Adapted from reference 51 .

C. NCA-IA insecticides as inhibitors of $\left[{ }^{3} \mathrm{H}\right] \mathrm{EBOB}$ binding in housefly head membranes and topical $\mathrm{LD}_{50}$ to houseflies with CYP450-inhibiting synergist (piperonyl butoxide). $\mathrm{r}=0.89, \mathrm{n}=34$. Adapted from reference 35 .

D. AVE insecticides as inhibitors of $\left[{ }^{3} \mathrm{H}\right]$ ave binding in housefly head membranes and topical $\mathrm{LD}_{50}$ to houseflies with CYP450-inhibiting synergist (piperonyl butoxide). $\mathrm{r}=0.83, \mathrm{n}=11$. Adapted from reference 55.

E. NCA-II isoxazoline insecticides as inhibitors of $\left[{ }^{3} \mathrm{H}\right]$ flu binding in Apis mellifera head membranes and potency $\left(1 / \mathrm{ppm} \mathrm{LC}_{50}\right)$ to Empoasca fabae $\mathrm{r}=0.84, \mathrm{n}=9$. Data from references 61 and 66.

F. NCA-II isoxazoline insecticides as inhibitors of GABA response of thoracic neurons and toxicity in Periplaneta americana. $n=3$. Data from reference 61 .

G. NCA-II meta-diamide insecticides as inhibitors of $\left[{ }^{3} \mathrm{H}\right] \mathrm{BPB}-1$ binding in housefly head membranes and dietary ppm $\mathrm{LC}_{70}$ to Spodoptera littoralis larvae. Toxicity data are given as high, medium or low shown as $<0.1,0.1$ and $10 \mathrm{ppm}$ respectively. $\mathrm{n}=11$ with deletion of $N$-methyl proinsecticides from the data set of Ozoe et al [68].

Figure 6. Four unique proposed Dm RDL GABA-R binding sites (homology model based on 3RHW). Left to right, one subunit in green (front) is displayed with helices M3, M1, M2: second subunit in red is left to right M3, M2, M1. NCA-IA, NCA-IB and NCA-II pesticides in the channel pore shown together (interactions with M2) and also shown separately maintaining the same relative positions. Ave at the interface of two transmembrane subunits. Amino acid residues are identified in Supplementary Material Fig. 4.

\footnotetext{
${ }^{1}$ Year for discovery or first introduction: a picrotoxinin 1875, b lindane 1945, c TETS 1949, d dieldrin 1949, e toxaphene 1951, $\mathbf{f}$ a-endosulfan 1961, g TBPS 1979, $\mathbf{h}$ avermectin 1985, i fipronil 1988, j EBOB 1988, k flu 2010, I mDA 2013, m BPB 2013
} 
Table 1

Properties of GABA receptor pesticide targets ${ }^{\mathrm{a}}$

\begin{tabular}{|c|c|c|c|c|c|c|}
\hline \multirow[b]{3}{*}{ Property } & \multirow[b]{3}{*}{ NCA-IA } & \multirow[b]{3}{*}{ NCA-IB } & \multicolumn{3}{|c|}{ NCA-II } & \multirow[b]{3}{*}{ AVE } \\
\hline & & & \multirow[b]{2}{*}{ isoxazoline } & \multicolumn{2}{|c|}{ meta-diamides } & \\
\hline & & & & mDA-7 & BPB-1 & \\
\hline Radioligand & {$\left[{ }^{3} \mathrm{H}\right] \mathrm{EBOB}$} & {$\left[{ }^{35} \mathrm{~S}\right] \mathrm{TBPS}$} & {$\left[{ }^{3} \mathrm{H}\right] \mathrm{flu}$} & - & {$\left[{ }^{3} \mathrm{H}\right] \mathrm{BPB}-1$} & {$\left[{ }^{3} \mathrm{H}\right]$ ave } \\
\hline \multicolumn{7}{|l|}{ Molecular size (\%) } \\
\hline Relative to ave $(\%)^{\mathrm{b}}$ & $36-40$ & $23-26$ & $59-60$ & $58-60$ & $57-58$ & 100 \\
\hline Extended length $\left(\AA{ }^{\mathrm{c}}\right)^{\mathrm{c}}$ & $12-13$ & $5-8$ & 20 & 16 & 20 & 19 \\
\hline Receptor example & Musca & mammal & Musca & Spodoptera & Musca & Musca \\
\hline \multicolumn{7}{|l|}{ Response to } \\
\hline GABA & inhib & inhib & inhib & - & inhib & no \\
\hline Glutamate & - & - & - & - & poor & - \\
\hline Fipronil & inhib & inhib & poor & - & enhance & no \\
\hline Cyclodiene & inhib & inhib & no & - & enhance & no \\
\hline Avermectin & inhib & - & inhib & - & inhib & inhib \\
\hline Inhibitor $\mathrm{SAR}^{\mathrm{d}}$ & yes & yes & yes & yes & yes & yes \\
\hline Temp coeff & positive & negative & - & - & - & - \\
\hline \multicolumn{7}{|l|}{ Resistance } \\
\hline IRAC classification & $2 \mathrm{~A}, 2 \mathrm{~B}$ & no & no & no & no & 6 \\
\hline Rdl dieldrin & yes & no & no & no & no & no \\
\hline
\end{tabular}

${ }^{\mathrm{a}}$ References given at appropriate sections in the text

${ }^{\mathrm{b}}$ Range of surface area and solvent accessible volume for each chemotype (See Supplementary Material Table 1 and Fig. 2)

${ }^{c}$ Extended length in the RDL GABA-R pore from this report

${ }^{\mathrm{d}}$ Structure-activity relationships (SAR) as inhibitors of radioligand binding, ${ }^{36}$ chloride uptake or GABA response predicts toxicity (see Fig.5 and Section 6.2). 